Unit of Clinical Biochemistry M Salinas

H Manero

and Rheumatology

Section

J Rosas

J Iborra

E Pascual

Hospital General Universitario de Alicante, Spain

Correspondence to: Dr E Pascual, Sección de Reumatología, Hospital General Universitario de Alicante, Maestro Alonso 109, 03010 Alicante, Spain.

Accepted for publication 27 June 1997

\title{
Comparison of manual and automated cell counts in EDTA preserved synovial fluids. Storage has little influence on the results
}

\author{
María Salinas, José Rosas, José Iborra, Herminia Manero, Eliseo Pascual
}

\begin{abstract}
Objective-To determine the precision and agreement of synovial fluid (SF) cell counts done manually and with automated counters, and to determine the degree of variability of the counts in SF samples, kept in the tubes used for routine white blood cell (WBC) counts-which use liquid EDTA as anticoagulant-at 24 and 48 hours at $4^{\circ} \mathrm{C}$, and at room temperature. Methods-To determine precision, cell counts were repeated 10 times-both manually and by an automated counter-in a SF sample of low, medium, and high cellularity. The variances were calculated to determine the interobserver variation in two manual $(M 1, M 2)$ and two automated cell counts $(\mathrm{C} 1, \mathrm{C} 2)$. The agreement between a manual (M1) and automated counter (C1) results, was analysed by the Bland and Altman method and the difference against the mean of the two methods was plotted. Then, the mean difference between the two methods was estimated and the standard deviation of the difference. To determine the effects of storage, $\mathrm{SF}$ samples were kept in a refrigerator at $4^{\circ} \mathrm{C}$, and at room temperature; cell counts were done manually (M1) and automatically (C1) at 24 and 48 hours and the changes analysed by the Bland and Altman method. The variances were com-
\end{abstract} pared using an $F$ test.

Results-(1) Precision. With the manual technique, the coefficients of variation were $27.9 \%, 14 \%$, and $10.7 \%$ when used for counting the SF with low (270), medium (6200), and high cellularities (25 000). With the automated technique the coefficients of variation were $20 \%, 3.4 \%$, and $2.9 \%$ in the same SF samples. In the fluids of medium and high cellularity, the variances of the automated cell counts were significatively lower $(F$ test, $p<0.002)$ than those of the manual counts. (2) Interobserver variation. The variance between C1 and C2 (25 SF) was significatively lower $(F$ test, $p<0.002)$ than that of the manual counts (41 SF). (3) Agreement between the two techniques (100 SF). For cellularities above 2000 cells $/ \mathrm{mm}^{3}$, the manual method gave results between $+10 \%$ to $-34 \%$ of the results obtained by the coulter. For cellularities below 2000 cells $/ \mathrm{mm}^{3}$, manual cell counts were between +60 to -1280 cells $/ \mathrm{mm}^{3}$ of those obtained by the automated counter. (4) Influence of storage. The coulter counts of SF samples preserved at $4^{\circ} \mathrm{C}$ showed less variance $(F$ test, $p<0.05)$ than the manual counts. The worst results were obtained in manual counts of SF samples kept at room temperature; these samples at 48 hours showed a variation between $-47 \%$ to $42 \%$ of the initial results.

Conclusions-Automated cell count of the SF offers advantages: it gives higher precision and consumes less time. The stability of the samples preserved in the EDTA tubes used for routine WBC counts is of additional interest, because if delay cannot be avoided, the results of the WBC counts are still accurate at 24 and even at 48 hours, at least for clinical purposes.

(Ann Rheum Dis 1997;56:622-626)

The white blood cell (WBC) count in synovial fluid provides information about the amount of inflammation present in the joints, and is the basis for the classification of synovial fluids (SF) into the categories of non-inflammatory, inflammatory, and septic. ${ }^{1-3}$ The WBC count is generally performed manually, using saline as a diluent to avoid the formation of a mucin clot, which would result from the use of haematological diluents containing acetic acid. $^{4}$

Different problems have been found in relation to the performance of the WBC counts in the SF; a poor reproducibility of manual WBC counts, ${ }^{5}$ as well as contradictory results in relation to the stability of the SF have been reported, emphasising the need of performing the procedure without delay. ${ }^{6}$ Counting by means of automatic counters has occasionally been done, but problems such as the error produced by fat globules have been found when the counts are performed by such a method. ${ }^{7}$

Our aim is to determine the precision and reproducibility of WBC counts of SF 
performed manually and also by means of an automated counter. We also have determined the stability of the counts after 24 and 48 hours using both methods of counting.

\section{Methods}

SAMPLES

During a period of three months, 100 samples of SF obtained from patients with different arthropathies were analysed. After the extraction, $5 \mathrm{ml}$ samples of each $\mathrm{SF}$ were placed in a tube containing EDTA (vacutainer EDTA (K3), Beckton and Dikinson).

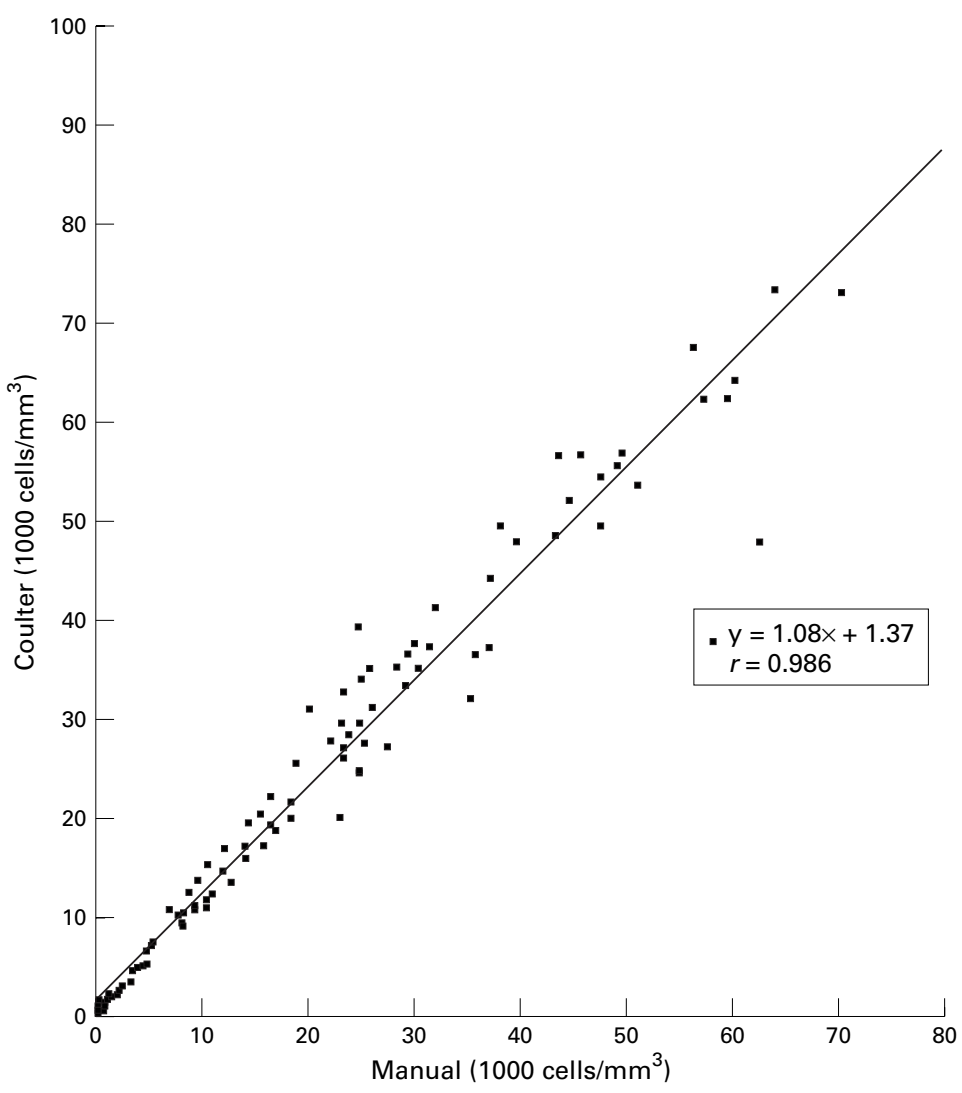

Figure 1 Comparison between an automated and a manual cell count in 100 samples of synovial fluids, showing an excellent correlation $(r=0.986)$.

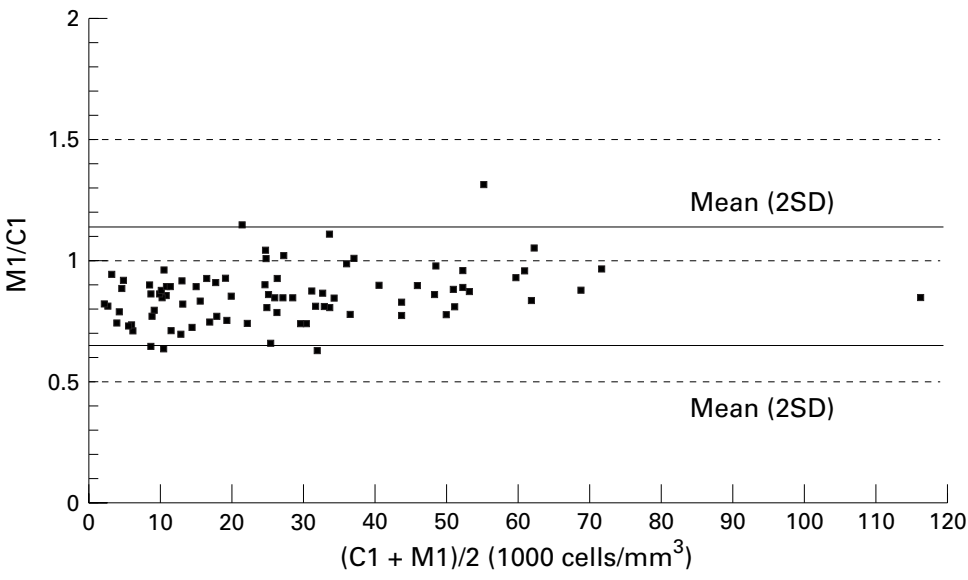

Figure 2 Ratio between manual (M1) and coulter (C1) counts (M1/C1) against the mean $(C 1+M 1) / 2$ (Bland and Altman ${ }^{11}$ (see Methods for details)). It shows that for cellularities above 2000 cells $/ \mathrm{mm}^{3}$, manual counts were between $+10 \%$ to $-34 \%$ of the corresponding counts done by a coulter machine.
TECHNIQUES

Manual counts were done after diluting the SF samples with saline, ${ }^{4}$ and using a haemacytometric chamber (Neubauer Improved). SF with low cell counts were performed in undiluted SF as is done with cerebrospinal fluid. ${ }^{8}$ All cell counts were done independently by two trained people (manual 1, M1 and manual 2, M2). Two different coulter machines (Coulter JT and Coulter S Plus IV, Coulter Electronics) were used for the automated counts (C1 and $\mathrm{C} 2$ ).

\section{CALCULATIONS AND STATISTICS}

Precision

To determine the precision of both the manual and automated techniques, 10 successive cell counts in the same SF were done using each technique, and the coefficient of variation was calculated. This procedure was done in three different SF samples with low, medium, and high cell counts to determine its influence on the precision of each of these techniques. The variances between the manual and automated techniques were compared for each fluid, using an $F$ test.

\section{Agreement}

To determine the interobserver variation of both techniques (manual and automatic), 41 SF samples were counted manually by the two observers (M1 and M2), and 25 SF samples by the two automated haematocytometers (C1 and C2), in both cases during the first hour after extraction. The coefficient of variation were calculated in all cases. Because of the non-normal distribution of the differences of the samples, a logarithmic tranformation was carried out. ${ }^{910}$ An $F$ test was used to compare the interobserver variances. To determine the agreement between the two methods, 100 SF were counted by both, and the resulting values analysed by the Bland and Altman method, ${ }^{11}$ in which the difference against the mean of both methods is graphically plotted, then the mean difference between the methods and the standard deviation of the differences is estimated. A logarithmic transformation was used in the fluids of more than 2000 cells $/ \mathrm{mm}^{3}$ because the differences between both methods were proportional to the cellularity of the samples. In the the samples with less than 2000 cells, the Bland and Altman method was used without logarithmic transformation. For better graphical representation of figure 2, we have used for this figure the ratio $\mathrm{M} 1 / \mathrm{C} 1$, instead of the logarithm of $M 1 / C 1(\log M 1-\log M 2)$. We also used a $\kappa$ index to determine the concordance between the two techniques to classify the SF into non-inflammatory and inflammatory (above and below 2000 cells $/ \mathrm{mm} 3$ ).

\section{Result of storage}

To determine the effects of storage, $58 \mathrm{SF}$ samples were kept in a refrigerator at $4^{\circ} \mathrm{C}$, and $43 \mathrm{SF}$ samples at room temperature. Cell counts were done manually (M1) and automatically (C1) at 24 and 48 hours, and the results analysed using the Bland and Altman method, after logarithmic transformation of 


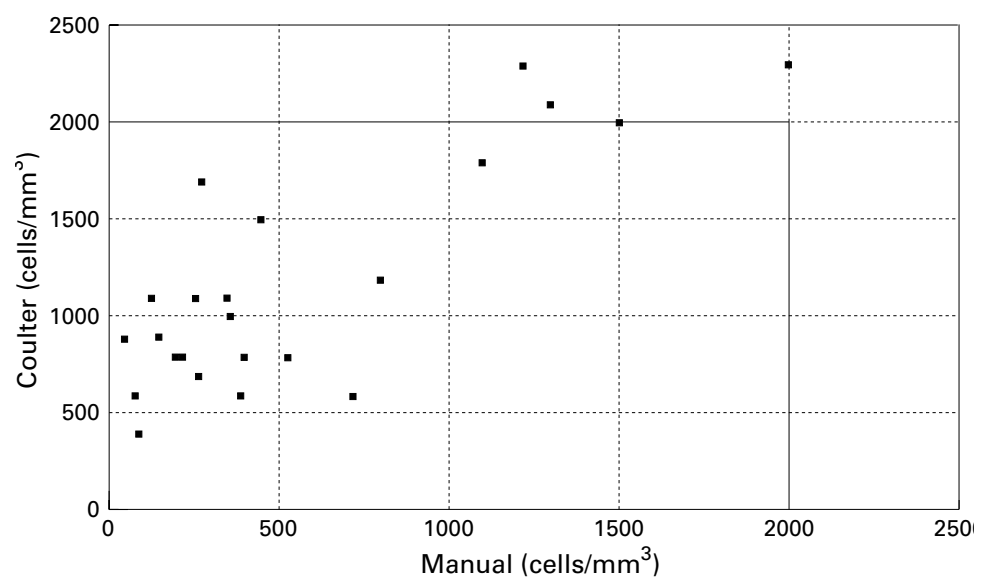

Figure 3 Manual and coulter counts in the samples in which manual counts were lowerlequal to 2000 cells $/ \mathrm{mm}^{3}$. Only three SF samples classified after manual counting as non-inflammatory $\left(<2000\right.$ cells $\left./ \mathrm{mm}^{3}\right)$, were classified as inflammatory $\left(>2000 \mathrm{cells} / \mathrm{mm}^{3}\right)$ by a count done with a coulter machine.

the results; the variances were also calculated and compared using an $F$ test.

\section{Results}

INTRAOBSERVER PRECISION

With the manual technique the mean cell counts of the three samples were 270,6200 , and 25000 cells $/ \mathrm{mm}^{3}$. The respective coefficients of variation for the manual counts were $27.9 \%, 14 \%$, and $10.7 \%$. The means of the automated cells counts in the same SF samples were 600, 8000, and 27500 cells $/ \mathrm{mm}^{3}$, and the respective coefficients of variation were $20 \%, 3.4 \%$, and $2.9 \%$. When applying the $F$ test to the variances between both methods, there were no significant differences in the low cellularity SF samples $(p>0.10)$. In the fluids of medium and high cellularity, the variances of the automated cell counts were significantly inferior $(p<0.002)$ to those of the manual counts, indicating that the automated cell counts are more precise in SF samples that show cell counts in the inflammatory range.

INTEROBSERVER VARIATION FOR MANUAL AND AUTOMATED CELL COUNTS

The coefficient of variation between both manual observers (M1 and M2) was $21 \%$ and $9 \%$ between both coulter counters ( $\mathrm{C} 1$ and C2). The variance of the comparison of the results obtained by both coulters $(0.0083)$ was

Table 1 Variations (mean (SD)) of the cell counts performed manually and with a coulter machine in samples kept at $4^{\circ} \mathrm{C}, 24$ and 48 hours (Bland and Altman method)

\begin{tabular}{llll}
\hline & 24 hours & 48 hours & Samples (n) \\
\hline Manual & $-31 \%$ to $32 \%$ & $-46 \%$ to $46 \%$ & 27 \\
Coulter & $-24 \%$ to $31 \%$ & $-28 \%$ to $38 \%$ & 58 \\
\hline
\end{tabular}

Table 2 Variations (mean (SD)) of the cell counts performed manually and with a coulter machine in samples kept at room temperature, 24 and 48 hours (Bland and Altman method)

\begin{tabular}{llll}
\hline & 24 hours & 48 hours & Samples (n) \\
\hline Manual & $-36 \%$ to $49 \%$ & $-47 \%$ to $42 \%$ & 34 \\
Coulter & $-32 \%$ to $45 \%$ & $-40 \%$ to $50 \%$ & 43 \\
\hline
\end{tabular}

Table 3 Variances of the relations of the cell counts in fresh samples and those at 24 and 48 hours. The comparisons of coulter counts (0 hours-24 hours, and 0 hours -48 hours) of samples at $4^{\circ} \mathrm{C}$ show lesser variation than the other methods and temperatures

\begin{tabular}{|c|c|c|c|}
\hline & 24 hours & 48 hours & Samples (n) \\
\hline Coulter $4^{\circ} \mathrm{C}$ & 0.00967 & $0.0184^{\star}$ & 59 \\
\hline $\begin{array}{l}\text { Coulter room } \\
\text { temperature }\end{array}$ & 0.0177 & 0.0273 & 27 \\
\hline Manual $4^{\circ} \mathrm{C}$ & $0.01852^{\star}$ & $0.0372^{\star}+$ & 43 \\
\hline $\begin{array}{l}\text { Manual room } \\
\text { temperature }\end{array}$ & $0.02178^{\star}$ & $0.0396^{\star} \dagger$ & 34 \\
\hline
\end{tabular}
coulter at $4^{\circ} \mathrm{C}$ at 48 hours (F test).

significantly inferior $(\mathrm{p}<0.002)$ to that of the manual counts $(0.03576)$.

AGREEMENT BETWEEN MANUAL AND AUTOMATED TECHNIQUES

For cellularities above 2000 cells $/ \mathrm{mm}^{3}$, in $95 \%$ of the samples, the manual method showed results between $+10 \%$ to $-34 \%$ of the results obtained by the coulters (figs 1 and 2). For cellularities below 2000 cells $/ \mathrm{mm}^{3}$, on $95 \%$ of the occasions, manual cell counts were between +60 to -1280 cells $/ \mathrm{mm}^{3}$ of those obtained by the automated counter. No SF that appeared as non-inflammatory (below 2000 cells $/ \mathrm{mm}^{3}$ ) in the automated counter, was classified as inflammatory in the manual count. Of the 23 SF samples of a total of 100 in which the manual cell count were classified as non-inflammatory, only three were classified as inflammatory by the coulter counter (fig 3). The $\kappa$ index was 0.91 .

INFLUENCE OF STORAGE

The variations in the EDTA preserved SF samples at 24 and 48 hours, depending on the temperature of storage $\left(4^{\circ} \mathrm{C}\right.$ and room temperature) and on the counting method used, are shown in tables 1 and 2 , which show the results in $95 \%$ of the samples. An example (coulter at 0 and 24 hours, $4^{\circ} \mathrm{C}$ ) is shown in figure 4.

The comparison of the variances is shown in table 3. It can be seen that the comparisons of coulter counts ( 0 hours-24 hours, and 0 hours -48 hours ) of samples at $4^{\circ} \mathrm{C}$ show lesser variation than the other methods and temperatures, although they only show significant differences with the counts performed manually ( $F$ test, $\mathrm{p}<0.05$ ). In all cases the variances were not large, and the measurements appeared appropriate for clinical use.

\section{Discussion}

Cell count of the SF is a basic procedure in the assessment of the degree of inflammation present in a joint. Although manual WBC count of the SF is the procedure that is generally recommended, we did not find any problem with the use of automated counters. Some newer counters may not accept samples other than blood. Our results show that the automated WBC counts have higher precision than the cell counts of the same SF performed manually, and that the precision is higher in the SF that is more cellular, the results being similar in cell counts below 2000 cells $/ \mathrm{mm}^{3}$. The 
interobserver variation was also better in the cell counts performed by automated means. Previously the use of automated cell counters has been discouraged because of possible error caused by fat droplets ${ }^{7}$ or other particles, as well as the possible damage that the SF cell counting could cause to the machines. Our use of EDTA to avoid SF clotting, which is the standard anticoagulant used in automated blood cell counting, instead of heparin may have helped to avoid such problems, which we did not encounter. The diagnosis of the patients was not recorded, as we already had experience with the technique and felt that the diagnosis did not influence the counting technique. At our institution, all SF samples are routinely examined while still fresh in the search for crystals; we did not find a significant amount of fat droplets in any of the SF. The count of the SF from patients with gout or calcium pyrophosphate crystal arthropathy was carried out without difficulty, but we did not specifically check whether in these SF samples the discrepancies between the results of the manual and the automated counts were larger

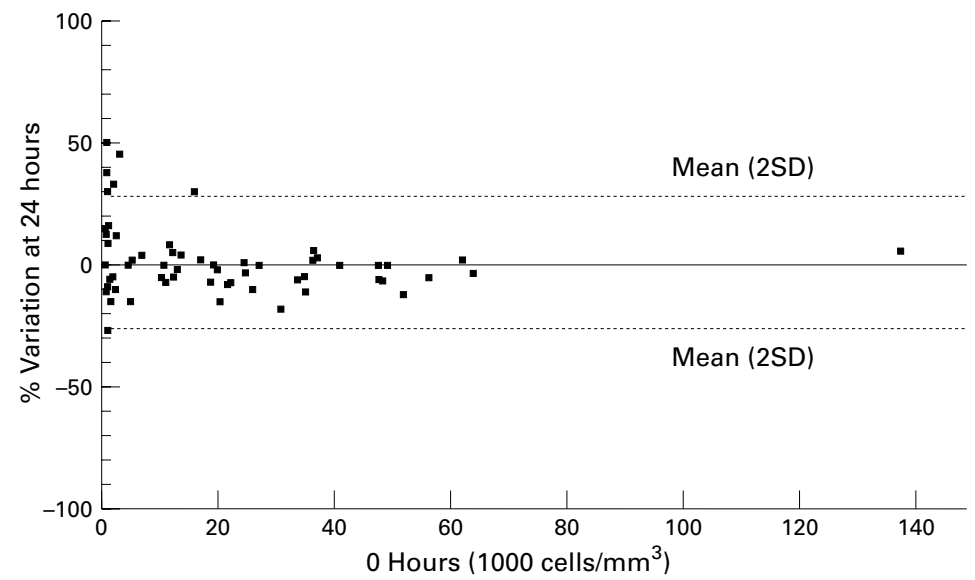

Figure 4 Ratio of coulter cell counts on fresh samples and aliquots kept at 24 hours at $4^{\circ} \mathrm{C}$ (Bland and Altman ${ }^{11}$ ). There is little variation in cell counts.

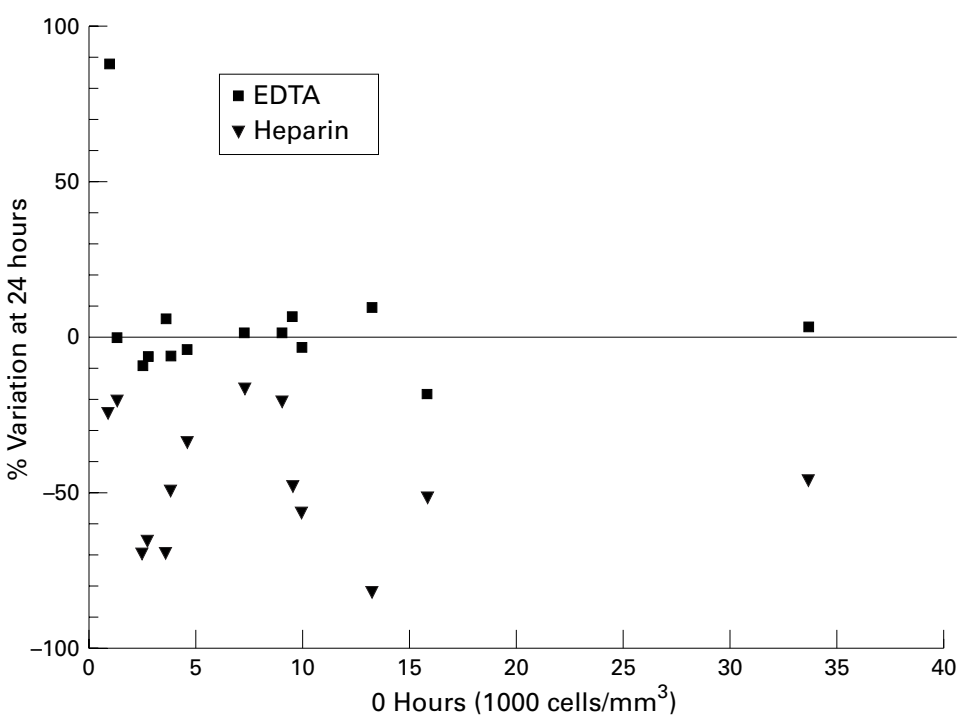

Figure 5 Ratio of coulter cell count preserved in EDTA and heparin, on fresh samples and at 24 hours at room temperature (Bland and Altman ${ }^{11}$ ). The samples kept in EDTA show little variation while those in heparin show a drop in their cellularity. than in the rest of the fluids, which might result from a possible counting error produced by the crystals. The result of the cell counts done by automated means is about $17 \%$ higher than those done manually. Normally the cell counting machines are regularly subjected to internal and external quality control, ${ }^{12}{ }^{13}$ which is not the case of manually performed cell counts. This control ought to decrease the probability of significant count errors either by a machine, or between them.

When both manual and automated methods are compared, although it may seem that the differences are numerically large $(-34 \%$ to $10 \%$ variation between the manual and the automated techniques), clinically both results seem appropriate, as, for instance, a SF with 5000 cells $/ \mathrm{mm}^{3}$ counted automatically, may show a manual count between 3500 and 5500 cells $/ \mathrm{mm}^{3}$; or a SF showing 60000 cells $/ \mathrm{mm}^{3}$, would show between 40000 and 66000 cells/ $\mathrm{mm}^{3}$ if performed manually. For noninflammatory SF (below 2000 cells $/ \mathrm{mm}^{3}$ ), automated counting also gives higher values, but not in proportion to the cellularity. Figure 3 shows that coulter counting does not give any cell count under 400 cells $/ \mathrm{mm}^{3}$ in SF samples with considerably lower manual counts. In this group manual counts seem preferable, and are best performed in undiluted SF samples. ${ }^{8}$

To our surprise, the cell counts performed after keeping the EDTA preserved SF 24 and 48 hours at $4^{\circ} \mathrm{C}$ were very close to the values obtained just after the fluid extraction. Not unexpectedly, the results at 48 hours were poorer, but still quite good. Of additional interest, results of counts done in SF preserved at room temperature were lower, but still reasonable. The decrease in the values obtained for the WBC counts at 24 and 48 hours was always small and the results still clinically appropiate.

The use of EDTA as anticoagulant probably was important for the preservation of the fluids, as our results differ from previous reports in which heparin was used and where a pronounced decrease in the WBC counts was noted. ${ }^{57}$ To explore this possibility further, we performed a small pilot study on $14 \mathrm{SF}$, of which we kept samples both in heparin and EDTA, and counted them with the same counter (C1) after extraction, and at 24 and 48 hours at room temperature. After 24 hours, in the group kept with heparin, we found a decrease in the cell count (mean (SD)) of 42.8 (21)\%, and a decrease of 47 (20)\% after 48 hours. In the fluids kept in EDTA the decreases were only $9.3(10) \%$ at 24 hours, and $5.1(25) \%$ (both with a significance of $\mathrm{p}<0.001$ in relation with the heparin kept samples, Mann-Whitney test, fig 5). These data strongly suggest that EDTA is a much more suitable preservative than heparin for the performance of synovial fluid counts. Preservation with heparin may explain the reported disagreement between cell counts performed by different laboratories. ${ }^{5}$

We did not attempt to explore the suitability of EDTA preservation in relation to differential counts or crystal identification, which with the 
present knowledge should always be done using fresh SF samples. Besides, we have not assayed the tubes that use a crystalline EDTA preparation as preservant; these EDTA crystals may cause error if used for crystal analysis. Also, EDTA tubes should not be used to preserve SF samples collected to perform determinations on which the influence of this preservant in not known.

In conclusion, automated cell count of the SF offers advantages: it gives greater precision and is less time consuming. The stability of the samples preserved in the EDTA tubes used for routine WBC counts is also of additional interest because, if a delay cannot be avoided, the results of the WBC counts are still accurate, at least for clinical purposes. If automated counting is used, a manual count on undiluted fluid should be done in SF of very low cellularity. Although our results of the cell counts done using EDTA preserved SF samples by automated means are superior, those of manual counts are also good, and either technique can be used depending on the personal preferences, experience, and facilities available.

This study was partially supported by the Ministry of Health FIS grant 1212/96.

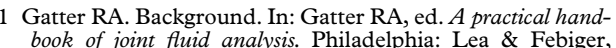
book of joint

2 Shumacher HR. Synovial fluid analysis. In: Kelley WN, Harris E, Ruddy S, Sledge CB, ed. Textbook of rheumatology. 5th ed. Philadelphia: WB Saunders, 1997: 609-25.

3 Cohen AS, Goldenberg D. Synovial fluid. In: Cohen AS, ed. Laboratory diagnostic procedures in the rheumatic diseases. Orlando: Grune \& Stratton, 1985: 40-53.

4 Gatter RA. The total and differential white blood cell count. In: Gatter RA, ed. A practical handbook of joint fluid analysis. Philadelphia: Lea \& Febiger, 1984: 21-8.

5 Schumacher HR, Sieck MS, Rothfuss S, Clayburne GM, Baumgarten DF, Mochan BS, et al. Reproducibility of synovial fluid analysis. A study among four laboratories. Arthritis Rheum 1986;296:770-4.

6 Keroleus G, Klayburne G, Schumacher HR Jr. Is it mandatory to examine synovial fluids promptly after arthrocentesis? Arthritis Rheum 1989;32:271-8.

7 Vincent J, Korn JH, Podwell C, Tully E. Synovial fluid pseudoleukocytosis. Arthritis Rheum 1980;23:1399-400.

8 Pascual E. Persistente of monosodium urate crystals, and low grade inflammation, in the synovial fluid of untreated gout. Arthritis Rheum 1991;34:141-5.

9 Altman DG, JL Bland. Comparing several groups using analysis of variance. BMJ 1996;312:1472-3.

10 Bland JM, Altman DG. Measurement error proportional to the mean. BMJ 1996; 313:106

11 Bland JM, Altman DG. Statistical methods for assesing agreement between two methods of clinical measurement. Lancet 1986;i:307-10.

12 Examination of the blood. In: Williams WJ, Beutler E, Erslev AJ, Litchman MA, eds. Hematology. 3rd ed. New York: McGraw-Hill, 1983:11-25.

13 Gulati GL, Hyun BH. The automated CBC: a current perspective. Hematol Clin North Am 1994;8:593-603.

\title{
Unusual and memorable
}

\author{
Series editor: Gary D Wright
}

A 57 year old woman with metastatic ovarian carcinoma presented with painful, swollen, stiff, hands. Examination showed pronounced thickened palmar fascia and flexor tendons, with fixed flexion deformities of her fingers. Mild sclerodactly was noted and there was red, tender swelling of the MCP and PIP joints of both hands (figures 1 and 2). There was no history of Raynauds or dysphagia and no other skin or joint involvement.

Palmar fasciitis and arthritis syndrome was first described as a paraneoplastic phenomenon with ovarian carcinoma in $1982 .{ }^{1}$ It has also been described in association with other malignancies. ${ }^{2}$ Although clinically similar to reflex sympathetic dystrophy it is usually bilateral and rapidly progressive with extensive fasciitis and inflammatory arthritis. The rheumatic symptoms may precede detection of the tumour leading to misdiagnosis. Histopathological examination shows pronounced fibrosis with little mononuclear infiltrate. Chemotherapy may improve the arthritis.
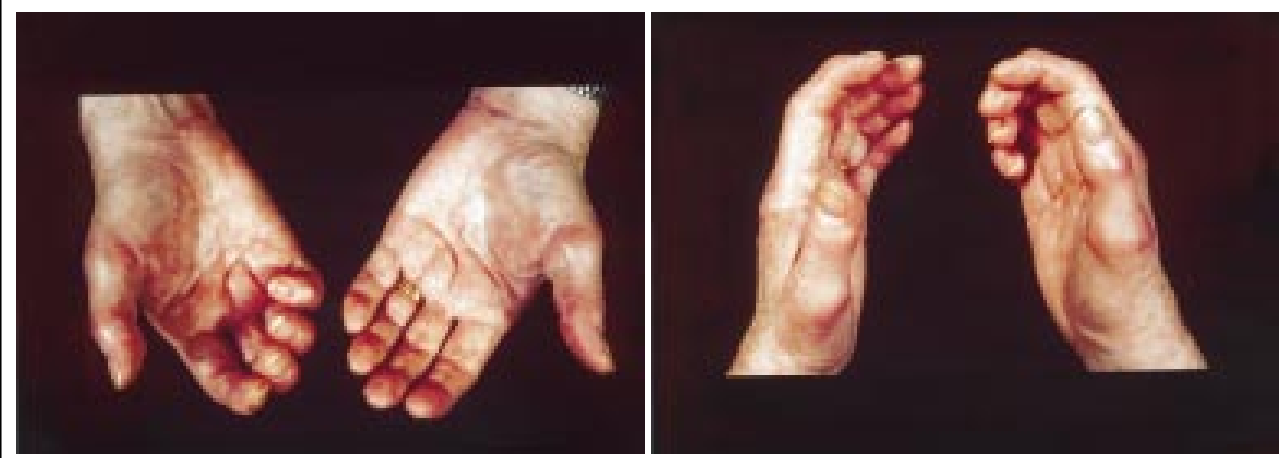

1 Medsger TA, Dixon JA, Garwood VF. Palmar fasciitis and polyarthritis associated with ovarian carcinoma. Ann Intern Med 1982;96:424-31

2 Pfinsgraff J, Buckingham RB, Killian PJ, et al. Palmar fasciitis and arthritis with malignant neoplasms: a paraneoplastic syndrome. Semin Arthritis Rheum 1986;16:118-25.

Contributors: GARY D WRIGHT, MICHAEL DOHERTy. Department of Rheumatology, City Hospital, Nottingham, NG5 1PB, United Kingdom. 